\section{ELECTRIC WELDING VOCATIONAL TRAINING FOR YOUTH IN ENTREPRENEURSHIP}

\section{PELATIHAN KEJURUAN LAS LISTRIK BAGI PEMUDA DALAM BERWIRAUSAHA}

\author{
Despiantini', Syafuri Musa', Dayat Hidayat ${ }^{3}$ \\ ${ }^{1}$ Universitas Singaperbangsa Karawang \\ ${ }^{2}$ Universitas Singaperbangsa Karawang \\ ${ }^{3}$ Universitas Singaperbangsa Karawang \\ despiantinianugrah@gmail.com
}

Jurnal Pendidikan Luar Sekolah

http://kolokium.ppj.unp.ac.id/

Jurusan Pendidikan Luar Sekolah

Fakultas Ilmu Pendidikan

Universitas Negeri Padang

Sumatera Barat, Indonesia

Volume 9, Nomor 1, 2021

DOI: $10.24036 /$ kolokium-pls.v9i1.459

Received 06 Maret 2021

Approved 11 April 2021

Published 22 April 2021

\begin{abstract}
Despiantini (1610631040010). Vocational training of electric welding for youth in Entrepreneurial Training Hall (BLK) Kab. Purwakarta. School of Education Study Program, Faculty of Teacher Training and Education Sciences, University of Singaperbangsa Karawang, 2020. The background of this study was the many unemployment that existed in Kab. Purwakarta which is mainly from the youth circles, and lack of skills among others in electric welding so lost to compete in the workforce. Thus the problem formulation of this research is how the implementation and results of vocational training of electric welding for the youth in entrepreneurship at the Training Hall (BLK) Kab. Purwakarta. The purpose of this research is to obtain an overview of the implementation and outcome of vocational training of electric welding for the youth in Entrepreneurship at the Kab work Training Hall. Purwakarta. The foundations of the theory used in this research include the concept of training. Training is a process of educative interaction between citizens studying with the training components. The training components include: raw input (raw input), instrumental input (input), environmental input, process, output (output), other input, and outcome (influence) This study used a qualitative approach with a case study method conducted at Kab Training Hall (BLK). Purwakarta. The number of research subjects was five respondents, one organizer, an instructor, and three people. The data collection techniques used in this study are observations, interviews, and documentation analysis. The stages involved in this training include the orientation stage, the exploration stage, and the member check stage. The results of the study as follows: (1) Kab Working Training Hall (BLK). Purwakarta has been conducting vocational training for electrical welding through planning, implementation, and assessment of 28 days of training @ 10 hours lessons/day with 16 people who study trained by one person instructor, and (2) District Training Hall (BLK). Purwakarta has trained 16 people of citizens learn in the mastery of SMAW 2G welding skills in accordance with the prevailing standards. Advice on the implementation of electrical welding vocational training among others so that the BLK can be equipped with electric tools that are still lacking.
\end{abstract}

Keywords: training, welding electricity, entrepreneurship

\author{
ABSTRAK \\ Despiantini (1610631040010). Pelatihan vokasi las listrik untuk remaja di Balai Latihan Kewirausahaan \\ (BLK) Kab. Purwakarta. Program Studi Sekolah Pendidikan, Fakultas Keguruan dan Ilmu Pendidikan,
}


Universitas Singaperbangsa Karawang, 2020. Latar belakang penelitian ini adalah banyaknya pengangguran yang ada di Kab. Purwakarta yang sebagian besar dari kalangan pemuda, dan kurangnya keterampilan antara lain dalam pengelasan listrik sehingga kalah bersaing dalam dunia kerja. Dengan demikian rumusan masalah penelitian ini adalah bagaimana pelaksanaan dan hasil diklat las listrik bagi remaja dalam berwirausaha di Balai Latihan Kerja (BLK) Kab. Purwakarta. Tujuan dari penelitian ini adalah untuk memperoleh gambaran pelaksanaan dan hasil diklat vokasi las listrik bagi remaja bidang Kewirausahaan di Balai Diklat kerja Kab. Purwakarta. Landasan teori yang digunakan dalam penelitian ini meliputi konsep pelatihan. Pelatihan adalah proses interaksi edukatif antara warga belajar dengan komponen pelatihan. Komponen pelatihan meliputi: masukan mentah (raw input), masukan instrumental (input), masukan lingkungan, proses, keluaran (output), masukan lain, dan hasil (influence) Penelitian ini menggunakan pendekatan kualitatif dengan metode studi kasus yang dilakukan di Kab. Balai Latihan (BLK). Purwakarta. Jumlah subjek penelitian adalah lima orang responden, satu orang penyelenggara, seorang pengajar, dan tiga orang. Teknik pengumpulan data yang digunakan dalam penelitian ini adalah observasi, wawancara, dan analisis dokumentasi. Tahapan yang dilakukan dalam pelatihan ini meliputi tahap orientasi, tahap eksplorasi, dan tahap member check. Hasil penelitian sebagai berikut: (1) Balai Latihan Kerja Kab (BLK). Purwakarta telah melaksanakan pelatihan vokasi untuk pengelasan listrik melalui perencanaan, pelaksanaan, dan penilaian 28 hari pelatihan@ 10 jam pelajaran/hari dengan 16 orang yang belajar dilatih oleh satu orang instruktur, dan (2) Balai Latihan Kerja Kabupaten (BLK). Purwakarta telah melatih 16 orang warga belajar penguasaan keterampilan las SMAW 2 G sesuai dengan standar yang berlaku. Saran pelaksanaan diklat las listrik antara lain agar BLK dapat dilengkapi dengan alat-alat listrik yang masih kurang.

Kata Kunci: pelatihan, pengelasan listrik, kewirausahaan

\section{PENDAHULUAN}

Perkembangan ekonomi di Indonesia sampai saat ini masih belum menunjukkan kemajuannya yang sejalan dengan zaman. Hal ini ditunjukkan salah satunya dengan masih banyaknya angka pengangguran yang dari tahun ke tahun semakin bertambah. Melambatnya ekonomi di Indonesia juga menjadi salah satu faktor meningkatnya jumlah pengangguran. Dengan keadaan ekonomi masyarakat Indonesia yang mayoritas masih didominasi oleh masyarakat yang berpenghasilan menengah ke bawah dan juga banyaknya pengangguran, Indonesia masih jauh dari harapan untuk dikatakan sebagai negara maju. Dalam hal ini diperlukan adanya pelatihan kerja dan cara memulai dalam berwirausaha. Pelatihan kerja ini sangat diperlukan dikarenakan masih banyak masyarakat bahkan sarjana meskipun jenjang pendidikan yang sudah tinggi namun pengalaman/skill dalam dunia kerja masih sangat minim. Pelatihan merupakan jenis kegiatan yang direncanakan, sistematis dan menghasilkan tingkat peningkatan keterampilan, pengetahuan dan kompetensi yang diperlukan untuk melakukan pekerjaan secara efektif (Gordon, 1992) dalam Sultana et al, (2012). Berwirausaha sekarang ini menjadi solusi terbaik dalam mengatasi banyaknya pengangguran karena dalam berwirausaha tidak diperlukan pendidikan yang tinggi melainkan modal. Sekarang ini program berwirausaha sangat didukung pemerintah dengan disediakannya badan-badan peminjaman modal seperti koperasi yang menyediakan modal bagi wirausahawan. Aktifitas kewirausahaan (entrepreneurial activity) di negara kita dewasa ini tergolong rendah. Ini ditunjukkan oleh jumlah individu yang aktif dalam memulai bisnis baru jika dinyatakan dalam persen total penduduk yang aktif bekerja relatif masih rendah. Untuk meminimalisir pengangguran di Kab. Purwakarta maka dibutuhkan peran dan kinerja dari lembaga pelatihan 
pemerintah maupun swasta agar dapat menyiapkan tenaga kerja yang terampil dan kompeten serta berdaya saing tinggi. Demikian pula lembaga pemerintah yang dimaksud yang berada di wilayah Kab. Purwakarta yaitu Balai Latihan Kerja. Dalam pelatihan kejuruan las listrik mayoritas warga belajarnya adalah dari kalangan pemuda yaitu pria. Karena itu adalah salah satu persyaratan dari perusahaan yang bekerjasama dengan pihak lembaga Balai Latihan Kerja (BLK) Kab. Purwakarta. Maka untuk memecahkan masalah tersebut, penulis merumuskan masalah yaitu, bagaimana pelaksanaan dan hasil pelatihan kejuruan las listrik bagi pemuda dalam berwirausaha di Balai Latihan Kerja (BLK) Kab. Purwakarta. Adapun tujuan dari penelitian ini adalah untuk memperoleh gambaran tentang pelaksanaan dan hasil pelatihan kejuruan las listrik bagi pemuda di Balai Latihan Kerja Kab. Purwakarta.

\section{METODE}

Pendekatan penelitian yang digunakan adalah pendekatan kualitatif. Metode yang digunakan dalam penelitian ini adalah metode studi kasus. Instrument penelitian yang digunakan adalah lembar observasi, pedoman wawancara, dan dokumentasi. Teknik pengumpulan yang digunakan antara lain observasi, wawancara, dan analisis dokumentasi.

\section{PEMBAHASAN}

Pelaksanaan pelatihan kejuruan las listrik tidak lepas dari kurikulum yang telah ditetapkan, yang meliputi tujuan pelatihan kejuruan las listrik yaitu memberikan pengetahuan, keterampilan, dan karakteristik berwirausaha yang bisa mendukung dalam pengembangan berwirausaha. Materi pelatihan kejuruan las listrik bertujuan untuk membangun karakteristik berwirausaha dengan cara pembinaan mental spiritual, pengembangan pengetahuan dan keterampilan serta menambah pengalaman warga belajar dalam membangun usaha. Pendekatan yang digunakan adalah partisipatif agar memberikan kesempatan seluas-luasnya kepada warga belajar untuk terlibat dalam perencanaan, pelaksanaan, dan penilaian pembelajaran. Metode yang digunakan adalah ceramah, tanya jawab, diskusi dan praktek lapangan. Media yang digunakan meliputi modul, infocus, dan alat mesin. Dari proses pelatihan kejuruan las listrik di Balai Latihan Kerja (BLK) Kab. Purwakarta, warga belajar mendapat pengetahuan, keterampilan, dan perkembangan karakteristik berwirausaha. Warga belajar dilatih menjadi seorang wirausaha yang profesional. Warga belajar terbentuk kedisiplinan setelah dilaksanakannya pelatihan. Penyampaian materi teori dan praktek oleh instruktur jelas dan mudah dipahami. Proses pembelajaran yang diterapkan pun sudah sesuai dengan kurikulum yang ada. Dengan pengetahuan, keterampilan serta pengalaman selama pelatihan, warga belajar merasa lebih percaya diri dan optimis dalam pekerjaannya akan berjalan dengan baik Setelah melaksanakan pelatihan, warga belajar kompeten dalam melakukan pengelasan SMAW posisi $2 \mathrm{G}$ sesuai dengan standar yang berlaku. Warga belajar siap dalam bekerja di perusahaan yang membutuhkan keahlian dalam pengelasan. Dasardasar keterampilan dan prosedur-prosedur keterampilan sudah dapat dilakukan dengan baik. Nilai kewirausahaan yang dimiliki warga belajar bukan hanya sekedar pada nilai-nilai ekonomi (benefit), namun nilai-nilai sosial dan budaya selain mampu menolong dirinya sendiri juga mampu menolong orang lain dalam bentuk gotong royong dan partisipasi. Setelah pelatihan tersebut, warga belajar siap untuk bekerja di suatu perusahaan. Motivasinya untuk langsung terjun ke dalam dunia kewirausahaan belum sepenuhnya. Warga belajar terkendala dalam 
Electric Welding Vocational Training for Youth in Entrepreneurship...

modal jika untuk langsung berwirausaha. Warga belajar akan mengumpulkan dari hasil bekerjanya tersebut untuk dijadikan sebagai modal dalam berwirausaha.

\section{KESIMPULAN}

Pelatihan kejuruan las listrik terdiri dari tiga tahap, yaitu tahap persiapan, pelaksanaan, dan penilaian. Materi yang diberikan pada pelatihan ini adalah teori dan praktek. Tujuan pelatihan kejuruan las listrik ini adalah untuk menambah pengetahuan dan keterampilan serta memotivasi para lulusan pelatihan dalam berwirausaha dan kesiapan kerja dalam fase peralihan. Pendekatan yang dilakukan dalam pelatihan ini adalah partisipatif. Metode yang digunakan dalam pelaksanaan pelatihan kejuruan las listrik ini adalah cermah, tanya jawab, diskusi, dan praktek. Evaluasi dilakukan per-job kemajuan dengan menilai aspek kognitif, afektif, dan psikomotor. Hasil dari pelatihan ini warga belajar mendapatkan keterampilan dalam pengelasan, kemampuan dalam berwirausaha, dan juga mendapat penghargaan berupa sertifikat. Hasil pelatihan kejuruan las listrik menunjukkan hasil yang cukup baik. Terlihat dari peningkatan pada karakteristik berwirausaha dan professional dalam memahami karakteristik berwirausaha, berkomitmen dalam pekerjaan, dan berkemauan untuk untuk melakukan sesuatu secara mandiri. Warga belajar mengetahui dan memahami tentang disiplin akademik, dasar-dasar keterampilan, melakukan prosedur-prosedur pekerjaan, dan memahami tentang hubungan sosialisasi atau bergaul dengan orang lain. Dalam persaingan berwirausaha warga belajar sudah memahami nilai-nilai dan aturan dalam berwirausaha. Berbagai karakteristik dan keahlian berbeda yang dimiliki warga belajar menjadi satu kesatuan/kelompok sehingga warga belajar dapat bekerjasama dengan cara mengeksplor kelebihan masing-masing anggota. Kekompakkan dan komunikasi yang baik antaranggota, mitra kerja, atau konsumen selalu dijaga dengan baik.

\section{DAFTAR RUJUKAN}

Fitriana, W., \& Elshap, D. S. (2015). Revitalisasi Peran pendidikan Luar Sekolah Dalam Pemberdayaan Masyarakat. Empowerment: Jurnal Ilmiah Program Studi Pendidikan Luar Sekolah, 4(1), 58-66.

Kamil, Mustofa, (2009), Pendidikan Nonformal. Bandung : Alfabeta

Kamil, Mustofa, (2010). Model Pendidikan dan Pelatihan (Konsep dan Aplikasi).

Kaswan, Ade Sadikin Akhyadi. (2015). Pengembangan Sumber Daya Manusia.

Moleong Lexy J. (2013), Metode Penelitian Kualitatif. Bandung : Rosdakarya

Pyrolysis, F. (2012). Pengaruh Yang Signifikan antara Metode Pelatihan, Materi Pelatihan, Trainer terhadap Efektivitas Pelatihan Otomotif Pada UPT BLK Dinas Sosial Tenaga Kerja dan Transmigrasi Kabupaten Kudus. 5-27.

Safitri, E. (2013). Pengaruh Pelatihan Dan Disiplin Kerja Terhadap Kinerja Karyawan. Jurnal Ilmu Manajemen (JIM), 1(4).

Sudjana, Djudju. (2004). Pendidikan Luar Sekolah : Wawasan, Sejarah Perkembangan, Falsafah, Teori Pendukung, Asas. Bandung : Falah Production

. . (2004). Manajemen Program Pendidikan, untuk Pendidikan Nonformal, dan Pengembangan Sumber Daya Manusia, Falah Production, Bandung.

Sugiyono, (2014). Metode Penelitian Kuantitatif Kualitatif dan R\&D, Bandung : Alfabeta.

Trisnamansyah, S. 2005. Konsep Konsep Dasar Pendidikan Luar Sekolah, Program Studi 
Pendidikan Luar Sekolah, Program Pascasarjana, Universitas Islam Nusantara, Bandung.

Turere, V. N. (2013). Pengaruh Pendidikan Dan Pelatihan Terhadap Peningkatan Kinerja Karyawan Pada Balai Latihan Teknis Pertanian Kalasey. Jurnal Riset Ekonomi, Manajemen, Bisnis dan Akutansi, 1(3), 10-19

ASM International (society) (2003). Trends in Welding Research. Materials Park, Ohio: ASM International. ISBN 0-87170-780-2

Blunt, Jane and Nigel C. Balchin (2002). Health and Safety in Welding and Allied Processes. Cambridge: Woodhead. ISBN 1-85573-538-5.

Cary, Howard B.; Helzer, Scott C. (2005), Modern Welding Technology, Upper Saddle River, New Jersey: Pearson Education, ISBN 0-13-113029-3

Hicks, John (1999). Welded Joint Design. New York: Industrial Press. ISBN 0-8311-3130-6.

Kalpakjian, Serope; Schmid, Steven R. (2001), Manufacturing Engineering and Technology, Prentice-Hall, ISBN 0-201-36131-0

Lincoln Electric (1994), The Procedure Handbook of Arc Welding, Cleveland, Ohio: Lincoln Electric, ISBN 99949-25-82-2

Weman, Klas (2003), Welding processes handbook, New York: CRC Press, ISBN 0-84931773-8

http://www.bphn.go.id/data/documents/91pp073.pdf

https://www.bps.go.id/pressrelease/2019/05/06/1564/februari-2019--tingkat-

pengangguran-terbuka--tpt--sebesar-5-01-persen.html

https://doi.org/10.1080/13608746.2011.577943

https://id.wikipedia.org/wiki/Las_listrik

https://www.pengelasan.net/welding-adalah/

http://digilib.uinsby.ac.id/17728/5/Bab\%202.pdf. 